\title{
Critical Success Factors and the Sustainability of Small Scale Horticulture Projects in Kiambu County, Kenya
}

\author{
Emma Namwei Kukubo 1 \\ Postgraduate Student \\ Department of Management Science \\ School of Business \\ Kenyatta University \\ Kenya \\ Rosemary James $(\mathbf{P h D})^{2}$ \\ Senior Lecturer \\ Department of Management Science \\ School of Business \\ Kenyatta University, Kenya
}

\begin{abstract}
This study sought to assess the critical success factors and the sustainability of small scale horticulture projects in Kiambu County, Kenya. The study examines how training programs, project financing, stakeholder involvement and production technology affect sustainability of small scale horticulture projects in Kiambu County, Kenya. The target population were all the horticultural projects that have been implemented in Kiambu County within a period of 5 years (2013-2018). The sample size was defined using Slovin's formula and respondents selected using stratified proportionate random sampling technique. The study used primary data which was collected using semi-structured questionnaires and collected data analysed using both content analysis and descriptive statistics. Inferential statistics entailed correlation and regression analysis that enabled determination of the relationship between the research variables. The study found out that the variation on the sustainability of horticultural projects in Kiambu County is explained by the studied factors. There was low implementation of training, project financing, stakeholder engagement and production technologies among the horticultural projects in Kiambu County hence optimum project sustainability was yet to be achieved. The study recommends that the project management personnel should highly prioritize training, project financing, stakeholder involvement and production technologies during the formulation and execution of the horticultural projects. Proper budget allocation to projects and internal controls will act to improve the sustainability of these projects.
\end{abstract}

Key Words: Financial Support, Horticultural production technology, Project Financing, Project sustainability, Training Programs.

\subsection{Background of Study}

The importance of agriculture both in our current and future world cannot be underscored. This is attributed to the fact that despite significant increase in global population, production of food has always been enough to allow the average capita food to grow substantially. Concerned with the rising numbers in the world population, there is consensus henceforth; farmers must be able to produce adequate food, water and agrochemical for each unit of land. Small scale farmers are further presented with additional opportunities as well as challenges brought about by globalization in the agricultural sector (Dees, 2017).

Although Africa is relatively wealthy with vast natural resources, small scale farmers especially in the rural environs in most developing nations still experience incidences of hunger and poverty. Most of the rural households depend greatly on agriculture either directly or indirectly with the sector contributing to a largely to the overall economy growth. This implies that agriculture should be an integral part of economy growth and economy development. However, despite this contribution in transforming the economies of many countries together with poverty alleviation, many African countries are yet to fully embrace such benefits (Wamalwa, and James, 2018).

Enhancement of horticultural produce focus on quality and increased production, while at the same time emphasizing on the need for sustainable practices and effectively linking the farmers to markets both locally and internationally (Hendriks, 2014). In East Africa, despite the increased production of horticultural products, coffee and tea remain the 
dominant players in the international trade market. Similarly, in Kenya, horticulture produce remains the second most contributor to foreign exchange in the agricultural industry contributing to over $15 \%$ of the country's annual GDP.

Specifically, Kiambu County is characterized by very fertile soils and proximity to the Kenya capital city, Nairobi. This combination makes it very prime for horticultural farming. Therefore, maximization of horticultural production is thus deemed necessary to fully utilize this potential (Stenger, Altmann, and Schreiner, 2016). Though projects play crucial role in fostering advancement in the horticultural sector in the region, complexity and the enormous challenges results in intended outcomes not being achieved (Siborurema, 2015).As such, the small-scale projects continue to be marginalized with the expected outcomes not being fully achieved. To understand the sustainability of these small-scale projects is paramount in improving the overall efficiency of the horticultural sector of not only Kiambu County but the entire country as well.

\subsection{Statement of the Problem}

Kiambu County is situated in the middle of the very fertile agricultural land with huge potential to increase on its horticultural activities given its abundant natural resources. However, the current scenario is that this potential has not been realized with most of the horticultural projects being established not sustainable (Nyabera, 2015). According to Usadolo and Caldwe, (2016) only less than $10 \%$ of the horticultural projects implemented in Kiambuhave been able to achieve the desired outcomes. In addition, most of the horticultural projects take a long to be executed with others failing within less a year of operation hence increasing concern to the underlying determinants of sustainability of these projects.

Empirically, the determinants of project sustainability have gained interest of scholars and researcher with various studies being undertaken. A study undertaken by Nyaga and James, (2018) on factors affecting sustainability of food security projects among the Maasai community revealed that community participation and finance level satisfactorily had a positive significant influence on sustainability of food security projects.Salat, and James, (2019) established that there was a strong correlation coefficient between sustainability of community-based health projects and resource mobilization and utilization in Mandera County.Anita, Geofrey, and Anne, (2019) established that Factors Affecting Sustainability of Donor Funded Food Security Projects in Tharaka South Sub-County to be community involvement and Institution capacity. While Odenyo (2018) found out those financial resources, mapping human resources, acquisition of physical resources and community participation have a positive effect on project sustainability. Other studies such as Bauske, and Meyer, (2015), Nandwani, (2018) and Meyerding, (2016) that point out low project sustainability in horticultural projects occur mostly due to lack of community awareness and improper feasibility studies.

This shows that the issue of sustainability of projects is still a great concern in developed and developing countries as evidenced by numerous cases of low project sustainability. However, the studies conducted have not been fully conclusive on the exact determinants undermining the sustainability levels of the projects implemented. In addition, horticultural sector in Kenya has not been fully explored. Understanding these determinants is imperative in ascertaining that the horticultural sector is geared positively in achievement of the Millennium development goals (MDGs) and the vision 2030 through formulation of projects is achieved. This study aimed to address this research gap and sought to assess the sustainability of small scale horticulture projects in Kiambu County, Kenya.

The study was guided by the following specific research objectives:

i. To determine the effect of training programs on sustainability of small scale horticulture projects in Kiambu County, Kenya

ii. To assess the effect of project financing on sustainability of small scale horticulture projects in Kiambu County, Kenya

iii. To examine the effect of stakeholder involvement on sustainability of small scale horticulture projects in Kiambu County, Kenya

iv. To determine the influence of production technology on sustainability of small scale horticulture projects in Kiambu County, Kenya

\subsection{Literature Review}

Sustainability refers to the ability of a project to be able to maintain substantial benefit for a considerable duration of time after its implementation. Sustainable projects ought to provide both short term and long-term outputs to the involved parties through allocation of resource to ensure continuous production of outputs in the long term (Bagheri and Hjorth, 2017). Sustainability of projects is measured through various sustainability dimensions including continued 
operation, active community participation, equitable distribution, institutional stability, continuous flow of benefits, maintenance of environmental stability and maintenance of project structure (O’Halloran, 2014).

The main indicators that can be used to access project sustainability which include systemic indicators such as culture and technology, and project benefits that act to access whether the outcomes of the projects have been attained (Chelunget, 2017). In this study, the indicators of project sustainability therefore entailed project quality outcomes, resource mobilization, project improvement, continuity of the project and financial viability. This enabled the determination of the capability of the project in achieving the intended project objectives.

\subsection{Training Programs and Project Sustainability}

These are programs designed and trained by NGOs or collaborating partners to impart specific skills on horticultural farmers through hands on experience and guidance to improve productivity and general farmers welfare. Adhola (2016) undertook a research on development projects in Kisumu central sub-county, Kenya. The study used the descriptive design approach. The study findings revealed that beneficiaries' involvement, training on project management and stakeholder need analysis are key in sustainability of women development projects. The study was however limited only to women development projects which tend to differ to other projects in other sectors such as horticultural.

Wamalwa, and James, (2018) did a study on critical success factors in the implementation of projects by nongovernmental organisation in Busia County, Kenya. A descriptive approach was adopted in which a target population of 96 participants was included in the study by answering to a structured questionnaire. The study found that there was a positive and significant relationship between communication; financing; local community involvement and staff training on the implementation of NGO projects.

Anita, Geofrey, and Anne, (2019) did a study on sustainability of Donor Funded Projects, Tharaka South Sub-County. The study employed a descriptive research design and sampling of respondents through simple random sampling. The population of the study entailed a total of 400 respondents who entailed project officers, beneficiaries, opinion leaders and 228 respondents were chosen as the study sample. The study established that trainings, institution capacity and community involvement were positively correlated to project sustainability. The study was however focused only on donor funded projects without considering projects in other sectors or regions.

\subsection{Project Financing and Project Sustainability}

Project Financing entails the projected cash flows of the project both for short term and long term financial obligations. Chelunget (2017) studied the effects of financial management practices on project performance taking a case of UasinGishu County, Kenya. The study employed stratified and random sampling techniques in selection of the respondents. The findings revealed that proper project budgeting significantly influenced project performance. However, the study only investigated the project performance aspect without consideration of the sustainability of the projects.

Wachira, and James, (2018) investigated critical success factors in the implementation of community-based projects in Kiambu county, Kenya. The study adopted a descriptive survey design followed by stratified random sampling technique to segment the project strata's of the targeted a population of 141 community based projects. The study further used purposive and simple random sampling techniques to zero in to the key respondents of 86 CBP leaders. The study concludes that community participation, management of funds, institutional capacity and monitoring and evaluation of the projects positively influence the implementation of community based projects in Kiambu County.

Odenyo, (2018) undertook a study on resource mobilization and women group projects empowerment, case of Vihiga County. The study targeted 491 projects initiated by the women selected using stratified random sampling. The respondents of the study comprised of officials of the women groups, project committee members and officials of the empowerment groups. Data collected using questionnaires was analysed using descriptive statistics. The study established a significant positive effect of community participation, financial resources and sustainability of the projects. The study recommended that the women empowerment groups require training on resource mobilization techniques to be able to manage and acquire additional resources and finances. According to this study therefore adequate financial resources ensure that the projects are successful and well empowered.

\subsection{Stakeholder Involvement and Project Sustainability}

Stakeholder Participation entails the process of involving people holding an interest in a project in day to day activities of any project. Nyabera (2015) conducted a study on the influence of stakeholder participation on implementation of projects in Kenya. The study established that in projects with stakeholders represented in the project governance structure, stakeholder participation in project initiation strongly influenced project implementation. This current study aimed at ascertaining whether the same prevails for the projects at Kiambu. 
Maina (2016) who studied the factors that influence effective implementation of projects with a key focus on AMREF Health Africa in Kenya. A set of descriptive statistics of frequency and mean tables were used to present the results of the study.

The study found that for effective project implementation it was vital to ensure stakeholders engagement throughout the course of the project. However, the study was not able to establish the role played by the stakeholders in the sustainability of the projects.

Ngundo, and James,(2018) analysed Project Management Practices and Implementation of Government Projects in Machakos County, Kenya. A population of 128projects implemented by the County Government of Machakos was targeted. The study concluded that project planning, stakeholder participation, monitoring and evaluation and technology significantly influenced implementation of government funded projects in Machakos County. The study recommends that the project team should establish a project plan which should be followed with aid of a project tool.

Salat, and James, (2019) did a study on project Management Strategies and Sustainability of Community Based Health Projects in Mandera County, Kenya. The target of the study was a total of 47 projects which were selected from Mandera County with the respondents being donors, community leaders, county health officials and health executives. The study used a descriptive research design and data collected by means of questionnaires. The study found out that community participation and project sustainability were positively correlated. Capacity building was also established to have a significant contribution towards the sustainability of the community based health projects. Therefore, increased participation by the community ensured that the projects were fully sustainable, and the current study investigated the same among horticultural projects in Kiambu County.

\subsection{Production Technology and Project Sustainability}

Horticultural production technologies are techniques of providing favourable environment and artificial climatic conditions to plants including processing of food harvest scientifically with the aim of optimizing costs, minimizing input and maintaining a steady production. Juma (2012) conducted a study on the determinants of donor funded projects in Bungoma. The study was undertaken using a descriptive research design and analysed using descriptive statistics. The study found out that project technology and finance systems influenced project sustainability to a very great extent. The study also established that adoption of information technology affected sustainability of the project to a very great extent. The study was however focused on Bungoma County and thus the findings may not be generalized to other regions of the country.

Wangeci (2013) set out a study to analyze determinants influencing performance of Agricultural projects with special reference to the NALEP projects in Ruiru District. The findings of the study were then analyzed both quantitatively and qualitatively. The study found out that adoption of modern agricultural techniques has a positive significant effect on sustainability of agricultural projects. However, it only focused on NALEP projects in Ruiru District without investigating other projects in other regions.

Lahijani, and Kalantari, (2017) undertook a review of farming technologies, a case of developed cities. The research constituted a literature review of technologies and projects used in agriculture. The study utilized resources from 62 different sources covering a time span of 2007 to 2016. The study established that technology forms a basis for development and planning for innovative and prospective agriculture. Integrating of technology in production was also found out to simultaneously add to food safety, reduce poverty and increase sustainability.

\subsection{Theoretical Review}

The theories that underpinned this study included Stakeholder's Theory, Institutional Theory and Resource Based Theory.

\subsubsection{Stakeholder Theory}

Stakeholder theory was introduced by Edward Freeman, (1963) and later advanced to various disciplines in explaining stakeholder involvement. According to this theory, the interests of the donors and beneficiaries are theorized to be in line with that of the stakeholders. The theory put the emphasis that through active involvement of the stakeholders in the project will translate in promoting the overall interests geared towards ensuring project sustainability. According to this theory, the roles played by the stakeholders include resource allocation, overseeing operations as well as monitoring and evaluation of the projects.

This theory is important to this study because a well-managed stakeholder engagement process leads to sustainable projects. The proposition of this theory to this study is that stakeholder involvement is a major determinant of sustainability of horticultural projects in Kiambu County, Kenya. The stakeholders are also theorized to contribute during to planning and development stages of a project and provision of the required resources such as technology, finances and trainings. As such, proper engagement of stakeholders is essential in attainment of more focused projects. 


\subsubsection{Institutional Theory}

Institutional theory was proposed and advanced by Scott (1995) in describing the structure of organizations and institutions. Institutional theory holds that firms have unique cultural and material characteristics that comprise of the agency, assumptions, values, identities that provide a framework through which activities are done. According to this theory, institutional sustainability is not always a feasible objective, nor even necessarily a desirable one in some instances. There is a clear need to improve the odds for sustainability in many overseas development activities.

The proposition of the theory to the study is that sustainability of horticulture projects tends to vary based on the project. According to this theory thus there is no uniformity of these factors influencing project sustainability due to differences in the resources allocated, project leadership, expertise and technology involved and technicality of the projects. Therefore, sustainability of the horticultural projects is only attained through proper understanding of the specific dynamisms surrounding the projects for them to be successful.

\subsubsection{Resource Based View Theory}

The Resource Based View Theory introduced by Wernerfelt, (1984) in explaining the role played by resources possessed by firms. Based on this theory, the internal organization strengths and weakness maybe managed through proper utilization of the available resources which aid in removal of any possible barriers. Assumptions of this theory is that there is heterogeneity in the resources possessed and organizations are not able to fully produce all theresources required for normal functioning which therefore necessitates acquisition of resources from the external environment so as to acquire competitive advantage.

According to the theory, sustainability of the projects implemented is determined by the ability to obtain the resources necessary to support its operations. Therefore, projects that have been allocated more resources tend to have greater sustainability levels compared to those with fewer resources. Availability of resources such as financial support, adequate training and technological infrastructure is theorized to positively affect project sustainability among horticultural projects in Kiambu County, Kenya.

\subsection{Research Methodology}

This study adopted the descriptive research design. The design enabled the determination of sustainability of small scale horticulture projects in Kiambu County, Kenya. The study targeted all the 90 horticultural projects that have been implemented in Kiambu County within a period of 5 years (2013-2018). As such, all the individuals involved either directly or indirectly with overseeing the implementation of various horticultural projects in Kiambu County were targeted. As such, the total estimated number of people dealing with horticultural projects at Kiambu County constituencies are 320 (NGCDB, 2018).

The sample size was defined using Slovin's formula (1960). By applying the formula, using an error margin of 10\%, a sample size of 76 respondents was studied. The number of respondents to be studied per region was identified by relating the number of respondents under each constituency in relation to the entire population. Stratified proportionate random sampling was adopted in selection of the sample respondents based on the categories on involvement in the horticultural projects namely Project Members, Project Executives and Technical officers.

The study used purely primary data collection methods using questionnaires. Descriptive analysis including frequency, proportions, and measures of mean were then done. Qualitative data analysis method was then employed to analyze data gathered using open end questions. Inferential statistics namely regression and correlation analysis were further used to enable determination of the relationship between the research variables. The analysed data was presented using tables and figures.

\subsection{Research findings}

\subsection{Descriptive Statistics}

\subsubsection{Training Programs and Sustainability of Small Scale Horticulture Projects}

To analyze the extent at which training programs influence sustainability of small scale horticulture projects in Kiambu County, Kenya; training policy framework, trained personnel community members training, and training programs frequency were measured. 
Indicators of Training Programs on Project Sustainability

\begin{tabular}{|l|r|r|}
\hline Training Programs and Project Sustainability & \multicolumn{1}{|l|}{ Mean } & \multicolumn{1}{l|}{ Std Dev } \\
\hline Training policy framework & 2.69 & 0.2243 \\
\hline Trained personnel & 2.98 & 0.3070 \\
\hline Community members training & 3.16 & 0.4661 \\
\hline Training programs frequency & 2.75 & 0.2455 \\
\hline
\end{tabular}

Source: Research Data (2019)

On community members being trained, the respondents indicated a moderate extent of influence having a mean of 3.16. However, the respondents indicated a small influence on there are adequate trained personnel, availability of a definite policy and training programs are organized frequently with means of 2.98, 2.69 and 2.75 respectively. This shows that there were low training levels geared towards the horticultural projects which may be attributed to poor preparation, lack of proper project leadership and inadequate resources allocated towards project training which tends to limit the nature of operations of the projects. This tends to concur with Wamalwa, and James, (2018) who did a study on critical success factors in the implementation of projects by non-governmental organisation in Busia County, Kenya and found that there was a positive and significant relationship between communication; financing; local community involvement and staff training on the implementation of NGO projects.

\subsubsection{Project Financing and Sustainability of Small Scale Horticulture Projects}

To determine the extent at which project financing influence sustainability of small scale horticulture projects in Kiambu County, Kenya, timeliness funds release, adequate funding, proper budget allocation and proper financial management were measured.

Indicators of Project Financingon Project Sustainability

\begin{tabular}{|l|l|l|}
\hline Project Financing and Project Sustainability & Mean & Std Dev \\
\hline Timeliness funds release & 3.66 & 0.6181 \\
\hline Adequate funding & 3.30 & 0.8735 \\
\hline Proper budget allocation & 2.97 & 0.5646 \\
\hline Proper financial management & 2.97 & 0.3224 \\
\hline
\end{tabular}

\section{Source: Research Data (2019)}

The respondents indicated that there was timeliness in the releasing funds to a large extent with a mean of 3.66. To a moderate extent, the respondents stated that adequate funding with a mean of 3.30. However, to a small extent, the respondents indicated there is proper budget allocation for the project and proper financial management having means of 2.97 and 2.97 and 2.64. Thus, indicating that project financing play a great role in how the projects get implemented. This is because sustainability of horticultural projects requires financial services that can support larger agriculture investments and agriculture-related infrastructure which is not easily attainable in small scale horticultural farmers. Mwangi (2014) also found out that despite adequate financial support having a positive impact on sustainability of NGO funded community projects, it was still lacking in most projects. This coincides with Odenyo (2018) who found out that financial resources, mapping human resources, acquisition of physical resources and community participation have a positive effect on project sustainability.

\subsubsection{Stakeholder Involvement and Sustainability of Small Scale Horticulture Projects}

This section sought to find out the extent of stakeholder involvement in horticultural projects in Kiambu. Specifically, the study investigated the number of stakeholders, monitoring and evaluation by the stakeholders, funding from the stakeholders and proper definition and structuring of stakeholders' participation.

\section{Indicators of Stakeholder Involvement on Project Sustainability}

\begin{tabular}{|l|l|l|}
\hline Stakeholder Involvement and Project Sustainability & Mean & Std Dev. \\
\hline Number of stakeholders & 3.41 & 0.5172 \\
\hline Monitoring and Evaluation by the stakeholders & 3.77 & 0.8141 \\
\hline Funding from the stakeholders & 3.70 & 0.7060 \\
\hline Proper definition and structuring of stakeholders' participation & 3.44 & 0.5496 \\
\hline
\end{tabular}

Source: Research Data (2019) 
To a large extent the respondents stated that there are proper Monitoring and Evaluation strategies by the stakeholders and there is enough funding from the stakeholders having means of 3.77 and 3.70 respectively. However, on the number of stakeholders for horticultural projects been on the rise and there is well-structured program definition and structuring of stakeholders' participation the respondents stated a moderate extent having means of 3.41 and 3.44. This implies that stakeholder involvement constitutes a crucial aspect of the horticultural projects sustainability.

Through participation, stakeholders feel ownership of projects and solutions and encourage accountability of the organizations offering service. This relates with Anita, Geofrey, and Anne, (2019) who established that community involvement and Institution capacity affected project sustainability to a large extent. In a similar manner, Nyaga and James, (2018) on factors affecting sustainability of food security projects among the Maasai community revealed that community participation had a positive significant influence on sustainability of food security projects.

\subsubsection{Production Technology and Sustainability of Small Scale Horticulture Projects}

The study also sought to determine the extent of production technology use on horticultural projects in Kiambu. Specifically, the study determined the technical capacity in production technologies, acceptability of production technologies, utilization of horticultural production technology and adequate horticultural production technology.

Indicators of Production Technology on Project Sustainability

\begin{tabular}{|l|l|l|}
\hline Production Technology and Project Sustainability & Mean & Std Dev \\
\hline Technical capacity in production technologies & 4.39 & 1.1259 \\
\hline Acceptability of production technologies & 2.51 & 0.2575 \\
\hline Utilization of horticultural production technology & 3.82 & 0.8382 \\
\hline Adequate horticultural production technology & 4.28 & 1.0500 \\
\hline Average Mean Score & $\mathbf{3 . 7 5}$ & $\mathbf{0 . 8 0}$ \\
\hline
\end{tabular}

Source: Research Data (2019)

To a very large extent, the respondents stated that technical capacity is a huge determinant of the implementation of new production technologies and that there is availability of adequate horticultural production technology facilities having means of 4.39 and 4.28 respectively. To a large extent also, the respondents indicated that there is frequent utilization of horticultural production technology with a mean of 3.82. However, to a small extent, the respondents argued that production technologies are not readily acceptable by users with a mean of 2.51 hence showing that there were difficulties in adaptation of the production technologies. Overall, production technologies not only simplify the production of horticultural products but also increases the rate of productions hence of much importance. In addition, Wangeci, (2013) found out that adoption of modern agricultural techniques has a positive significant effect on sustainability of agricultural projects. WhereasLahijani, and Kalantari, (2017) undertook a review of farming technologies, a case of developed cities and established that integrating of technology in production simultaneously added to food safety and increase sustainability.

\subsection{Regression analysis}

Regression analysis was used to establish the relationship that exists between the research variables. Model Summary

\begin{tabular}{llll}
\hline $\mathbf{R}$ & R Square & Adjusted R Square & Std. Error of the Estimate \\
\hline $.722 \mathrm{a}$ & 0.669 & 0.603 & 0.06095 \\
\hline
\end{tabular}

a. Predictors: (Constant), Training Programs, Financial Support, Stakeholder Involvement, Production Technology Source: Survey Data (2019)

The coefficient of determination $\mathrm{R}$ square indicates that $66.9 \%$ of the variation on the sustainability of horticultural projects in Kiambu County is explained by the studied factors. This further implies that only $33.1 \%$ changes in the horticultural project sustainability are accounted by factors not included in the model.

4.3 ANOVA results

\begin{tabular}{llllll}
\hline & Sum of Squares & Df & Mean Square & F & Sig. \\
\hline Regression & 66.556 & 3 & 22.185 & 45.153 & $.000 \mathrm{a}$ \\
Residual & 94.828 & 193 & 0.491 & & \\
Total & 161.384 & 196 & & & \\
\hline
\end{tabular}

Source: Survey Data (2019) 
The ANOVA results for regression coefficients indicate that the significance of the model is 0.000 is which than both 0.01 and 0.05 . This thus shows that the model was highly significant in explaining the relationship that exists between the study variables. Hence, implying a good fit for the model since it shows a significant influence of; Training Programs, Financial Support, Stakeholder Involvement, Production Technology on horticultural projects sustainability.

\subsection{Regression Coefficients}

\begin{tabular}{llllll}
\hline & \multicolumn{2}{c}{ Unstandardized Coefficients } \\
& & Std. Error & $\begin{array}{l}\text { Standardized } \\
\text { Coefficients } \\
\text { Beta }\end{array}$ & t & Sig. \\
\hline (Constant) & 0.441 & 0.235 & & 1.876 & .062 \\
Training Programs & -0.369 & 0.099 & -0.315 & -3.742 & .000 \\
Financial Support & 0.668 & 0.104 & 0.455 & 6.43 & .000 \\
Stakeholder Involvement & 0.617 & 0.076 & 0.568 & 8.086 & .000 \\
Production Technology & 0.076 & 0.036 & 0.395 & 2.089 & .047 \\
\hline
\end{tabular}

Source: Survey Data (2019)

From the regression model coefficients results obtained, the predictive model thus developed by the study is; $\mathrm{Y}=-0.441$ $-0.369 \mathrm{X}_{1}+0.668 \mathrm{X}_{2}+0.617 \mathrm{X}_{3}+0.076 \mathrm{X}_{4}$; Where $\mathrm{Y}$ is Project Sustainability, $\mathrm{X}_{1}$ is Training Programs, $\mathrm{X}_{2}$ is Financial Support, $\mathrm{X}_{3}$ is Stakeholder Involvement and $\mathrm{X}_{4}$ is Production Technology. This implies that an increase in the project training programs will result in decreased sustainability of the projects which could be due to the allocations and funds required for the training initiatives. Similarly, Wamalwa, and James, (2018) who did a study on critical success factors in the implementation of projects by non-governmental organisation in Busia County, Kenyafound that there was a significant relationship between communication; financing; local community involvement and staff training on the implementation of NGO projects.Ngundo, and James, (2018) analysed Project Management Practices and Implementation of Government Projects in Machakos County, Kenyaand found out that project planning, stakeholder participation, monitoring and evaluation and technology significantly influenced implementation of government funded projects in Machakos County.Adhola (2016) also revealed that beneficiaries' involvement, training on project management and stakeholder need analysis are key in sustainability of women development projects.

\subsection{Summary}

The study aimed to assess the sustainability of small scale horticulture projects in Kiambu County, Kenya. The population for the study was all the horticultural projects that have been implemented in Kiambu County within a period of 5 years (2014-2018). The study used purely primary data which was collected using semi-structured questionnaires and analysed using both content analysis and descriptive statistics including measures of central tendencies such as means, frequency distribution and standard deviations. While the inferential statistics entailed correlation and regression analysis that enabled determination of the relationship between the research variables.

The established that there was inadequate training geared towards the horticultural projects indicating a moderate extent attributed to poor preparation, lack of proper project leadership and inadequate resources allocated towards project training which tends to limit the nature of operations of the projects. The study found out adequate financing of the horticultural projects in Kiambu County was far from being achieved which impaired the project sustainability. The study also found out that the expected level of stakeholder engagement in the horticultural projects was still yet to be attained with numerous areas requiring increased participation of the stakeholders. Additionally, it was found out that despite the hugerole played by production technologies, its adoption was only adopted to a small extent.

\subsection{Conclusions}

The study concludes that training, project financing, stakeholder engagement and production technologies determined the sustainability. However, these determinants are concluded to be minimally considered during the formulation and implementation of the horticultural projects hence resulting in unsustainable projects. The study also makes the conclusion that the horticultural projects in Kiambu County still experience low sustainable levels despite the numerous measures undertaken by both the government and involved stakeholders.

The study also concludes that due to the unsustainability of the horticultural projects the expected outcomes of the horticultural projects to the farmers, Kiambu County and the economy are not easily attainable. The study also makes the conclusion that the effect of these determinants tends to vary based on the determinant hence they ought to be 
treated separately. The study further concludes that the current sustainability of the horticultural projects is largely accounted by training, project financing, stakeholder engagement and production technologies adopted.

\subsection{Recommendations}

The study recommends the project management personnel to highly prioritize training, project financing, stakeholder involvement and production technologies during the formulation and execution of the horticultural projects. The study also recommends proper budget allocation to projects, internal controls, timeliness of releasing funds securing adequate funding, effective planning on allocation of funds and effective approval of funds which will act to improve the sustainability of these projects. In addition, the study recommends that proper budgetary plan and allocations should be highly considered during the projects' formulation process. This will prevent any malpractices such as mismanagement of funds from occurring which tend to hamper project sustainability.The study also recommends that the government should put in place appropriate policies that favor the implementation of horticultural projects in not only Kiambu County but also other regions in Kenya. Additionally, the management should constantly ensure that the set regulations are well adhered to.

\section{References}

Adhola, (2016).Determinants of Sustainability of Women's Development Projects Funded By Non- Governmental Organizations Kisumu Central, Kenya.Unpublished Masters of Art Project, University of Nairobi.

Anita, M. M., Geofrey, K. G., \& Anne, S. (2019). Factors Affecting Sustainability of Donor Funded Food Security Projects in Tharaka South Sub-County, TharakaNithi County, Kenya. Asian Journal of Agricultural Extension, Economics \& Sociology, 1-7.

Chelunget, D., (2017). Effect financial management practices on project performance in UasinGishu County, Kenya. International Journal of Economics, Commerce and Management, 5(5).

Dees, J. G. (2017). The Meaning of Social Entrepreneurship.In Case Studies in Social Entrepreneurship and Sustainability (pp. 34-42).Routledge.

Bagheri, A., \&Hjorth, P. (2017).Planning for sustainable development: a paradigm shift towards a process-based approach.Sustainable Development, 15, 83-96.

Hendriks, K., Stobbelaar, D. J., \& Van Mansvelt, J. D. (2014). The appearance of agriculture: an assessment of the quality of landscape of both organic and conventional horticultural farms in West Friesland. Agriculture, ecosystems \& environment, 77(1), 157-175.

Juma, K., (2012). An Examination into Factors Affecting Sustainability Of Donor Funded Community Development Projects in Bungoma County. MBA Project, Kenyatta University.

Kanyanya, L., (2014). Community training on water technology and sustainability of water projects in Shianda Division.Unpublished MBA Project, University of Nairobi.

Karanja G., M.,( 2014). Influence of management practices on sustainability of youthincome generating projects in Kangema District, Murang'a County, Kenya. International Journal of Education and Research 2(2)

Lahijani, A., \& Kalantari, S. (2017). A review of vertical farming technology: A guide for implementation of building integrated agriculture in cities. In Advanced Engineering Forum (Vol. 24, pp. 76-91).Trans Tech Publications.

Maina, M., (2016).Total quality and competitive advantage of firms in the horticultural industry in Kenya.Trans Tech Publications.

Bauske, E. M., Bachman, G. R., Bewick, T., Bradley, L., Close, D., Durham, R., \& Meyer, M. H. (2015).The case for a national strategic plan for consumer horticulture research, education, and extension.HortTechnology, 25(4), 477-479.

Meyerding, S. G. (2016). Change Management Study of Horticulture 2015-Conditions and Success Factors.Journal of Organisational Transformation \& Social Change, 13(2), 123-146.

Mwangi, J., (2016). Factors Influencing Sustainability Of Non Government Organizations Funded Community Projects In Kenya: A Case Of Action Aid Funded Project In Makima Location, Embu County.Unpublished MBA Project, University of Nairobi.

Ngundo, P. N., \& James, R. (2018).Project Management Practices and Implementation of Government Projects in Machakos County, Kenya.International Journal of Economics, Business and Management Research,

Nandwani, D. (Ed.). (2018). Urban Horticulture. Springer International Publishing.2(06), 236-253.

Nyabera, (2015).Influence of stakeholder participation on implementation of projects in Kenya: a case of Compassion International assisted projects in Mwingi sub-county.Unpublished Thesis, University of Nairobi.

Nyaga, J., \& James, R. (2018). Factors Affecting Sustainability Of Food Security Projects Among The Masaai Community. In Kajiado County, Kenya.Research journali's Journal of Sociology, 6(7). 
O'Halloran, M. (2014).The Awareness of Stakeholder Management amongst Project Managers in the Construction Industry in Ireland.Journal of project management, 2 (3) 32-70

Odenyo, C. (2018). Influence of Resource Mobilization on Sustainability of Women Group Projects in Vihiga County, Kenya (Doctoral dissertation, Kenyatta University).

Salat, A. M., \& James, R. (2019). Project Management Strategies and Sustainability of Community Based Health Projects in Mandera County, Kenya. Journal of Business Management, Entrepreneurship and Development, $1(1), 1-15$.

Siborurema, J., (2015). The Effects Of Projects Funding On Their Performance In Rwanda. International Journal of Economics, Commerce and Management, 3(8).

Stenger, M., Altmann, M., \& Schreiner, M. (2016).New strategic approaches for promoting the diffusion of innovations within the horticultural sector.EURAGRI $e$.

Theuri, B., (2014). Determinants of project sustainability in the health sector.Unpublished MBA Project, University of Nairobi.

Usadolo, S. E., \&Caldwel, M. (2016).A stakeholder approach to community participation in a rural development project.Sage Open, 6(1), 2158244016638132.

Wachira, G. E. \& James, R. (2018).Critical success factors in the implementation of community based projects in Kiambucounty, Kenya. International Journal of Economics, Business and Management Research 2(4).

Wamalwa, T., \& James, R. (2018). Critical success factors in the implementation of projects by non-governmental organisation in Busia County, Kenya. The Strategic Journal of Business and Chnage Management, 5(2), 11011108.

Wangeci, M., (2013).Determinants influencing performance of Agricultural projects with special reference to the NALEP projects in Ruiru District.Unpublished MBA Project, Kenyatta University. 